\title{
SSR-based analysis of clonality, spatial genetic structure and introgression from the Lombardy poplar into a natural population of Populus nigra L. along the Loire River
}

\author{
Nicolas Chenault ${ }^{1}$, Sophie Arnaud-Haond ${ }^{2}$, Mary Juteau ${ }^{1}$, Romain Valade ${ }^{1}$, José-Luis Almeida ${ }^{3}$, \\ Marc Villar ${ }^{1}$, Catherine Bastien ${ }^{1}$ and Arnaud Dowkiw ${ }^{1}$
}

${ }^{1}$ UR 0588 Amélioration, Génétique et Physiologie Forestières, INRA, CS 40001 Ardon, 45075 Orléans Cedex 2, France

2 IFREMER, Laboratoire Environnement Profond, Centre de Brest, BP 70, 29280 Plouzané, France

${ }^{3}$ UE 0995 Génétique et Biomasse Forestières, INRA, CS 40001 Ardon, 45075 Orléans Cedex 2, France

*: Corresponding author : Arnaud Dowkiw, email address : arnaud.dowkiw@orleans.inra.fr

\begin{abstract}
:
A scarcity of favourable habitats and introgression from exotic cultivars are two major threats to black poplars (Populus nigra L.) in Europe. Natural vegetative propagation contributes to maintenance of the species in areas where seedling recruitment is limited. Exhaustive sampling of all mature trees in a natural $P$. nigra stand (413 individuals at recorded positions), genotyping at 11 SSR loci, and a standardized analysis framework resulted in a precise description of clonality in terms of (a) frequency, (b) spatial growth form, and (c) impacts on the overall spatial genetic structure (SGS). The high proportion of replicated genotypes detected resulted in a genotypic richness $(R)$ of 0.47 . Up to 18 ramets were found per multilocus lineage (MLL), but $95 \%$ of MLLs contained fewer than five ramets (Pareto index $\beta=1.07$ ). No significant difference in vegetative propagation potential was found between genders. Uneven spatial distribution of ramets, with clustering of clonal ramets (aggregation index $A_{c}=0.62$ ) and near-zero intermingling between MLLs (clonal dominance index $D_{c}=0.99$ ), resulted in a 'phalanx' clonal growth form, explaining most of the SGS observed over short distances $(0-20 \mathrm{~m}, \mathrm{Sp}=0.0324)$. Although they did not exhibit the typical columnar shape of the Lombardy poplar ( $P$. nigra var. italica), five trees were found to be probable $\mathrm{F}_{1}$ hybrids of this old and widely distributed cultivar.
\end{abstract}

Keywords : Populus nigra ; Lombardy poplar ; Clonality ; Spatial genetic structure ; Introgression ; Clonal growth form 


\section{Introduction}

42 Various subspecies of black poplar (Populus nigra L.) have been proposed on the basis

43 of morphological traits; however, variation may be the result of the species' wide 44 distribution, ranging from the British Isles to Western Asia and from the Mediterranean 45 coast of Africa to Northern Europe, excluding Scandinavia (Dickmann and Kuzovkina 46 2008). This pioneer species is found in the early successional stages of riparian 47 woodlands and is considered an indicator of the health and biodiversity of these ecosystems (Rotach 2004). Although P. nigra has little commercial use per se, it is considered a key species in numerous European breeding programmes. In 2009, $66 \%$ of 50 the poplar cuttings sold by French nurseries were $P . \times$ euramericana Dode interspecific 51 hybrids (Paillassa 2010), resulting from crossing male black poplars with female 52 American eastern cottonwoods (P. deltoides Bartr.).

The species is threatened by extinction in several parts of its natural range as a

54 result of agriculture, urbanization and other human activities, which have altered both 55 the area available for colonization and the dynamics of floodplains, thus hindering seed 56 dispersal and germination and favouring latter successional hardwood trees (Lefèvre et 57 al. 1998). Even though P. nigra is classified as being of 'Least Concern' in the IUCN red list of threatened species (IUCN 2010), it is thought that there are, for example, only about 7000 trees left in Great Britain, and of these only about 600 are females (Cooper 60 2006). Recent surveys in the North-Western part of its range indicate that the species 61 survives mainly as scattered relicts, most of which were vegetatively propagated and 62 planted by humans (Koskela et al. 2004; Smulders et al. 2008b). National programmes 63 for the conservation of genetic resources have been established in many European 64 countries, under the collaborative EUFORGEN (European Forest Genetic Resources) 
65 programme (Frison et al. 1995), making black poplar a model species for ex- and in-situ 66 conservation genetics (Lefèvre et al. 2001b).

67 Like most poplar species, black poplar is dioecious and anemophilous. The seeds 68 are released in considerable numbers, they have virtually no dormancy and need a 69 substrate that is continuously wet for a four-week period to allow them to settle and 70 establish (Guilloy-Froget et al. 2002). P. nigra is also capable of vegetative propagation 71 when biotic (e.g., human, birds) or abiotic (e.g., flood, wind) disturbances lead to the 72 stimulation of dormant primordia in the roots and shoots of either damaged plants or 73 translocated fragments (Barsoum 2002). Levels of clonality ranging from 0 to $97 \%$ (i.e., 74 proportions of sampled trees with identical genotypes) have been reported in several 75 natural European P. nigra populations (Arens et al. 1998; Barsoum 2002; Barsoum et 76 al. 2004; Cottrell et al. 1997; Koskela et al. 2004; Legionnet 1997; Pospiskova and 77 Bartakova 2004; Pospiskova and Salkova 2006; Rathmacher et al. 2010; Smulders et al. 78 2008b; Storme et al. 2004; Winfield et al. 1998).

79 To facilitate rigorous studies of population and conservation genetics, the 80 frequency, spatio-temporal dynamics, and impacts of clonality must be known. Failing 81 to consider clonality in studied populations can lead to erroneous conclusions, 82 particularly when only a few genotypes predominate or when the sampling schemes 83 used are inappropriate as a result. In addition, both theoretical and empirical studies 84 have highlighted the ecological significance and evolutionary implications of clonality. 85 Because vegetative regeneration is possible even when seedling establishment is 86 impaired or rare, new habitats can be utilized and recovery from disturbances can 87 commence; this has been extensively documented in the American aspen, 88 P. tremuloides (Mock et al. 2008). Although no general trend has been established, it 
89 has been suggested that clonality affects population genetics parameters such as

90 effective population size, linkage disequilibrium, and heterozygosity (Balloux et al.

91 2003; Yonezawa et al. 2004). At the local scale, uneven spatial distribution of clonal

92 ramets can generate spatial genetic structure (SGS) in established populations (Reusch

93 et al. 1999). Clonality-driven SGS can have important consequences for reproduction in

94 dioecious or self-incompatible species (Charpentier 2002). SGS can also occur in the

95 absence of clonality as a consequence of limited gene dispersal (Epperson 2007;

96 Vekemans and Hardy 2004) or selection in heterogeneous environments (Epperson 97 1990).

98 Cultivated poplars are considered to represent another threat to P. nigra in

99 Europe; there are two reasons for this. First, they have the same water and soil

100 requirements as autochthonous $P$. nigra populations, thus leading to habitat exclusion

101 (Lefèvre et al. 2001a). Second, gene flow from cultivated trees may lead to

102 introgression (also known as "introgressive hybridization") from exotic species such as

103 P. deltoides or P. trichocarpa or from allochthonous P. nigra gene pools (Cagelli and

104 Lefèvre 1995; Vanden Broeck et al. 2005). P. nigra cv. Italica Du Roi (synonymous

105 with P. pyramidalis Rozier, P. italica (Du Roi) Moench, and P. fastigiata Foug.), also

106 known as the Lombardy poplar, is certainly the most ancient poplar cultivar and the one

107 with the widest distribution. Although it was first reported in Lombardy, Italy, at the

108 very beginning of the XVIII ${ }^{\text {th }}$ century, there has been some speculation about its origins

109 (Wood 1994), the two main options being (i) that a mutation in P. nigra occurred in

110 Italy and (ii) that it was introduced to Italy from Central Asia. Its timber has been used

111 for building, but its columnar shape also makes it a notable visual element in the

112 landscape. Five cuttings were introduced to France in 1745 and the first plantings were 
113 along the Loing canal ( 100km from our study site) (Pelée de Saint-Maurice 1762)

114 before Napoleon I promoted its planting across the Empire (Stettler 2009). It was

115 introduced into England in 1758, and into the United States in 1784 (Wood 1994).

116 Nowadays, despite its poor timber quality, the Lombardy poplar is commonly found in

117 rural and urban landscapes across the temperate zone. It is currently unclear whether

$118 P$. nigra cv. Italica is a single clone or if it comprises several genotypes that all exhibit

119 the distinctive columnar habit. Although most Italica-like trees are males, a few female

120 columnar $P$. nigra trees or cultivars have been reported, one of them being P. nigra L.

$121 \mathrm{cv}$. Thevestina (Dode) Bean. The reference cultivar found in the International Poplar

122 Commission database (http://www.populus.it/) is a male and is referred to as "San

123 Giorgio". The Lombardy poplar is densely branched and is often planted as windbreaks

124 or as single trees; thus it is supposed to be a major pollen producer. Moreover, since the

125 cultivar is part of the P. nigra species, barriers against introgression into autochtonous

126 wild P. nigra populations could be assumed to be low. A few previous studies have,

127 however, reported introgression levels (i.e., the proportion of potential $\mathrm{F}_{1}$ siblings

128 originating from Italica) of only $0-1.6 \%$ (Imbert and Lefèvre 2003, Tabbener and

129 Cottrell 2003, Vanden Broeck et al. 2004).

130 Here, we report on an exhaustive sampling strategy involving accurate

131 geopositioning and SSR genotyping in a natural population belonging to a European

132 Intensive Study Site (EVOLTREE ISS Loire - Zone 4) and representative of numerous

133 P. nigra populations in France (i.e., mature populations with significant levels of

134 anthropogenic disturbance). Beyond the usual genetic diversity estimates, major outputs

135 from this study include: (i) the quantification and spatial description of clonality using a

136 recently defined standardized analysis framework; (ii) an evaluation of the proportion of 
137 SGS that is attributable to the clonal growth form; and (iii) the identification of

138 Lombardy poplar introgression events with high confidence levels.

139

\section{Materials and methods}

142 Study site and plant material

143 The study site (7 ha, $915 \mathrm{~m}$ long) is located alongside the Loire River near the city of

144 Saint-Ay, France $\left(47^{\circ} 51^{\prime} \mathrm{N} / 1^{\circ} 45^{\prime} \mathrm{E}\right)$ (Fig. 1). Part of it belongs to the Saint-Mesmin

145 French National Natural Reserve. Aircraft laser altimetry (data from Direction

146 Régionale de l'Environnement de l'Aménagement et du Logement, Service Loire et

147 Bassin Loire Bretagne, Orléans, France, 2002) revealed a curvilinear depression 148 suggestive of a past meander of the river (Electronic Supplementary material 1). We,

149 therefore, hypothesize that most of the study site originates from a sandy island that

150 once merged with the riverbank. This is a common phenomenon on this dynamic river

151 system (Gautier and Grivel 2006). Aerial pictures from 1949 onwards (public domain

152 data from Institut Géographique National, Paris, France) reveal that: (i) the merging 153 occurred before 1949; (ii) mature P. nigra trees, although at lower densities, have been 154 present since 1949; and (iii) the study area has not been cultivated during that period.

155 Anthropogenic disturbance, however, is highly probable in this suburban area. It may 156 have taken several forms, such as grazing, cutting fodder or fuel wood, dumping garden

157 waste, and path clearing. Clearing is particularly obvious in the north-eastern extremity 158 of the study site. The land adjacent to the river floods frequently, but most of the study 159 site (north of the path) is located above usual flood level. Capillarity, however, can lead 160 to temporary water accumulation in the lowest points of the depression during very 
161 severe flood events (Saint-Mesmin French National Reserve Administrator, pers. 162 comm.). Black poplars represent at least $75 \%$ of the trees in the study area (amounting 163 to 60 trees / ha). They are not restricted to this area as mature trees can be found on both 164 sides of the river and also on most of the islands located nearby. Willows (Salix alba L.) 165 compete with black poplars on the bank of the river. Other pioneer - and interestingly 166 alien - tree species are found as scattered individuals (Juglans regia L., Acer negundo 167 L.) or groups of trees (Robinia pseudoacacia L., Prunus mahaleb L.). Although 168 considered to be post-pioneer species, the other trees that are present (Quercus robur L., 169 Acer platanoides L., Acer pseudoplatanus L., Acer campestre L, Fraxinus excelsior L.) 170 are also indicative of an open-habitat. As expected in such an open space with 171 heterogeneous soil conditions, more than 40 herbs, grasses and shrubs have been 172 identified (Saint-Mesmin French National Reserve Administrator, pers. comm.). A 173 significant part of the ground flora is indicative of high nitrogen availability (Urtica

174 dioica L., Lamium maculatum L., Galium aparine L.). Hygrophilous species such as 175 Iris pseudacorus L., Glechoma hederacea L. and Agrostis stolonifera L. are restricted to 176 the flood-prone areas (south of the path), since water availability declines sharply with 177 elevation.

178 Except for a few seedlings immediately adjacent to the river, juvenile trees were 179 absent. All sexually mature trees were inventoried (Fig. 1) and their location determined 180 by triangulation using a DT610 electronic digital theodolite (Sokkia Topcon, Mâcon, 181 France). When this technique could not be applied because of topographical constraints, 182 a S500 centimeter precision surveying system was used instead (Leica Geosystems, Le 183 Pecq, France). Sex was determined by looking at the flowers at various dates (>1 184 observation date per individual). 
Sweden), and girth at breast height were recorded for all studied trees. In the case of trunks sprouting from a common base), the girth of each stem was measured and the maximum value recorded. Both parameters exhibited relatively Gaussian distributions.

190 Height and girth ranged from 5.2 to $31.7 \mathrm{~m}$ and from 25 to $409 \mathrm{~cm}$, respectively, and the two parameters were highly correlated (Electronic Supplementary Material 2).

Tree ages were assessed for a sample of 20 single-stemmed individuals covering most of the observed range of variation in girth (individuals exceeding $250 \mathrm{~cm}$ girth

194 could not be evaluated due to technical constraints). Increment core samples were

195 collected at breast height. After drying, transverse longitudinal sections were cut from 196 each core. Because core analysis of black poplar wood is very difficult, two assessors 197 counted tree rings in a double-blind manner using 6x magnifying lenses. Microscopic 198 analysis did not improve reliability since false-rings were even more likely to be 199 mistaken for true rings. The mean divergence between operators was $20 \%$, and the

200 resulting tree ages (averages of the two estimates) varied between 9.5 and 52.5 years 201 (Electronic Supplementary Material 3). The overall correlation with girth was 202 sufficiently strong $\left(\mathrm{r}_{\text {Spearman }}=0.82\right.$, Electronic Supplementary Material 3) to consider 203 girth ranking as a good predictor of age ranking, at least for single-stemmed individuals. 204 Many Lombardy poplars have been identified on both sides of the Loire River, 205 in the urban area surrounding the study site, and within the study site itself. All of them 206 are clearly planted ornamental trees. Thirteen large individuals close to the study site 207 were selected for genotyping (Fig. 1). Eleven of these were located on a campsite south208 west of the study area $(153 \leq$ girth $\leq 255 \mathrm{~cm})$. Core-analysis was conducted on one of 
209 these (girth $=212 \mathrm{~cm}$ ), and the resulting age estimate was 34.5 years. The two other

210 individuals studied were growing very close to each other on the northern edge of the

211 study site $($ girth $=130$ and $134 \mathrm{~cm})$.

212 Young fresh leaf material was collected from the thirteen Lombardy poplars and

213 the $413 P$. nigra trees in the inventory and stored at $-80^{\circ} \mathrm{C}$ whilst awaiting DNA

214 extraction. Each stem of clumped trees was sampled to verify that they represented a

215 single genotype.

216

217 DNA extraction and SSR analysis

218

219 DNA was extracted from single leaves using a DNeasy 96 Plant Extraction kit (Qiagen,

220 Courtaboeuf, France) according to the manufacturer's instructions.

221 Genotyping was based on the following 11 unlinked nuclear SSRs (with their

222 corresponding linkage group): PMGC2852 (I), PMGC667 (II), PMGC486 (III), 223 PMGC2235 (IV), PMGC2838 (V), PMGC2578 (VI), PMGC61 (VIII), PMGC333 (XI), 224 PMGC14 (XIII), PMGC433 (XVI) (http://poplar2.cfr.washington.edu), and WPMS05 225 (XII) (Smulders et al. 2001; Van der Schoot et al. 2000).

226 The Polymerase Chain Reaction was carried out in a volume of $10 \mu \mathrm{L}$, which 227 contained $1 \mu \mathrm{L}$ template DNA and $9 \mu \mathrm{L}$ of the following mix: $1 \times$ PCR buffer, $1.5 \mathrm{mM}$ $228 \mathrm{MgCl}_{2}, 62.5 \mu \mathrm{M}$ dNTPs mix (all from Invitrogen, Cergy-Pontoise, France), $0.2 \mu \mathrm{M}$ 229 primers (Eurofins MWG Operon, Ebersberg, Germany), $0.02 \mu \mathrm{M}$ fluorescently labelled 230 forward primer with either 6-FAM, HEX (Eurofins MWG Operon) or NED (Applied 231 Biosystems, Courtaboeuf, France) fluorescent dyes, and $0.25 \mathrm{U}$ Taq polymerase 232 (Invitrogen). Amplification was conducted in a GenAmp 9700 thermocycler (Applied 
233 Biosystems) for 30 cycles, each with the following profile: a 30 s DNA denaturation 234 step at $94{ }^{\circ} \mathrm{C}$, a $30 \mathrm{~s}$ annealing step at 50 or $55^{\circ} \mathrm{C}$ depending on primers, and a $60 \mathrm{~s}$ 235 extension step at $72{ }^{\circ} \mathrm{C}$. The final extension step was extended to $6 \mathrm{~min}$. As the last denaturation step, a mix containing $2 \mu \mathrm{L}$ amplified DNA, $7 \mu \mathrm{L}$ 237 Formamide and $0.25 \mu \mathrm{L}$ 400HD-Rox size marker (Applied Biosystems) was maintained 238 at $95{ }^{\circ} \mathrm{C}$ for 3 min. The fragment separation was then performed in an ABI Prism 3100 239 Genetic Analyser (Applied Biosystems). The software GENOTYPER 3.7 (Applied 240 Biosystems) was used to score the SSR data.

242 Clonality detection and description

244 Identification of multilocus genotypes (MLG) and multilocus lineages (MLL) was 245 based on procedures implemented in GENCLONE 2.0 (Arnaud-Haond and Belkhir 2007) 246 and followed the standardized method proposed by Arnaud-Haond et al. (2007).

247 The genotypic resolution associated with each possible combination of analysed 248 loci was computed as the resulting number of distinct MLGs (Arnaud-Haond et al. $2492005)$.

250 Keeping only one ramet per identified MLG, and taking into account departures 251 from Hardy-Weinberg equilibrium as measured by Wright's inbreeding coefficient $\left(F_{i s}\right)$, 252 the probability $\left(p_{g e n}\right)$ of occurrence of each observed genotype was estimated according 253 to Young et al. (2002):

254 $p_{g e n}\left(F_{i s}\right)=\prod_{i=1}^{l}\left[\left(f_{i} g_{i}\right)\left(1+z_{i} F_{i s(i)}\right)\right] 2^{h}$ 
255 where $l$ is the number of loci, $h$ is the number of heterozygous loci, $f$ and $g$ are 'round256 robin' allelic frequency estimates of the observed alleles $f$ and $g$ at the $i^{\text {th }}$ locus, and $257 z_{i}=1$ (or -1$)$ if the $i^{\text {th }}$ locus is homozygous (or heterozygous).

258 When $n$ ramets with a genotype identical to a previously encountered MLG are 259 detected in a sample population $(N)$, the probability $\left(p_{s e x}\right)$ of these being derived from 260 distinct reproductive events can be estimated following Parks and Werth (1993):

261 $p_{\text {sex }}\left(F_{i s}\right)=\sum_{i=n}^{N} \frac{N !}{i !(N-i) !}\left[p_{\text {gen }}\left(F_{i s}\right)\right] i\left[1-p_{\text {gen }}\left(F_{i s}\right)\right]^{N-i}$

The significance of $p_{\text {sex }}$ was considered from the first re-encounter $(n=1)$.

To ascertain the uniqueness of MLGs with missing data (i.e., unamplified loci), such MLGs were examined on a case-by-case basis after removing the missing loci 265 from the entire dataset. Based on the recalculated $p_{s e x}$ estimates, these MLGs were either 266 designated as being unique or were pooled with another MLG into a MLL. Although

267 somatic mutations can be hypothesized, a similar approach was used to group MLGs 268 that differed at only one locus into MLLs, in order to account for possible scoring 269 errors.

The genotypic richness $(R)$ of the population was computed as $R=(G-1) /(N-$ 271 1) where $G$ is the number of MLLs, and $N$ the number of sampled trees (Dorken and 272 Eckert 2001).

273 For subsequent analyses at the MLL level, MLL $\geq 3$ (with three or more ramets) 274 were reduced to their dominant genotype while $\mathrm{MLL}_{=2}$ (with two ramets) were 275 assigned either (i) the heterozygous genotype at the mismatching locus if the other 276 genotype was homozygous (i.e., accepting the miscoded homozygote hypothesis) or (ii) 277 the genotype with the most frequent allele at the locus that differed (i.e., accepting the 278 somaclonal mutation hypothesis). 
279 In order to characterize the MLL size $\left(N_{R}\right.$, number of ramets) frequency 280 distribution, a cumulative function of the Pareto distribution was fitted to the data as 281 proposed by Arnaud-Haond et al. (2007). This function takes the form $F_{\geq X}=$ const. $X^{-}$ $282 \beta$ where $F_{\geq X}$ is the frequency of ramets belonging to a MLL $\geq X$ (with $X$ or more ramets). 283 The shape parameter $(\beta)$, also called the patchiness exponent, measures the relative 284 importance of large vs. small MLLs. $\beta$ increases exponentially with increasing evenness 285 of distribution. A graphical representation of $\log \left(F_{\geq X}\right)$ vs. $\log (X)$ and its associated 286 coefficient of determination $r^{2}$ were generated to check the quality of the Pareto 287 approximation.

288 Two spatial descriptors were computed for each MLL: (i) $d_{\max }$, the maximum 289 distance between ramets, and (ii) $\bar{d}_{\text {neighb. }}$, the average distance between nearest 290 neighbours. The relationships between $N_{R}$ and these two parameters were investigated.

291 The aggregation index $\left(A_{c}\right)$ proposed by Arnaud-Haond et al. (2007) was 292 calculated using GENCLONE 2.0 as:

$293 A_{c}=\left(p_{s g}-p_{s p}\right) / p_{s g}$

294 where $p_{s g}$ is the average probability of clonal identity of all sample unit pairs and $p_{s p}$ is 295 the average probability of clonal identity among pairwise nearest neighbours. The 296 significance of $A_{c}$ was assessed by a 10000-permutation test.

297 In order to quantify the degree of intermingling between MLLs, the clonal 298 dominance index $\left(D_{c}\right)$ was calculated following Ohsako (2010) for each $\mathrm{MLL}_{\geq 3}$ as:

$299 \quad D_{c}=\left(N_{R}-1\right) /\left(N_{T}-1\right)$

300 where $N_{R}$ is the MLL size (number of ramets) and $N_{T}$ is the total number of trees present 301 within the minimal convex envelope containing all ramets of the MLL. 
303 Detection of introgression from the Lombardy poplar

304

305 CERvus 3.0.3 (Marshall et al. 1998) was used to detect potential $F_{1}$ hybrids of the

306 Lombardy poplar in the identified MLLs. The multilocus profile of each Lombardy

307 poplar tree examined was tested for parentage assignment by simple exclusion (Jones

308 and Ardren 2003). The following two criteria were applied for each pairwise

309 comparison: (i) a minimum of eight typed loci in common, and (ii) a maximum of one

310 mismatch corresponding to putative false homozygote coding. Individual probabilities

311 of non-exclusion $\left(p_{\text {non-excl. }}\right)$ with both parents unknown were calculated using CERVUS

$312 \quad 3.0 .3$ according to Jamieson and Taylor (1997).

313

314 Genetic diversity

315

316 Deviations from a 1:1 sex-ratio were assessed at tree and MLL levels using chi-square 317 tests.

318 ARLEQUIN 3.5 (Excoffier et al. 2005) was used to compute neutral genetic

319 diversity parameters at the MLL level: observed $\left(H_{o}\right)$ and expected $\left(H_{e}\right)$ heterozygosities

320 (Nei 1978), number of alleles per locus $(A)$, effective number of alleles per locus $\left(A_{e}\right)$

321 (Hartl and Clark 1997), and Wright's inbreeding coefficient $\left(F_{i s}\right)$ per locus and sample

322 (Weir and Cockerham 1984). Departures from Hardy-Weinberg equilibrium were

323 revealed by bilateral exact tests on $F_{i s}$.

324

325 Spatial genetic structure

326 
327 SGS was explored by spatial autocorrelation analysis using GENCLONE 2.0. Multilocus 328 kinship coefficients $\left(F_{i j}\right)$ according to Loiselle et al. (1995) were computed for all pairs 329 of sampling units (i.e., trees or MLLs). $F_{i j}$ values were averaged within a given distance 330 class $d$ to produce $\bar{F}_{(d)}$ values. In an isotropic bi-dimensional space, the pairwise 331 genetic relationships between sample units are expected to vary linearly with the natural 332 logarithm of the geographic distance. The Sp statistic defined by Vekemans and Hardy 333 (2004), which enables comparisons among species independent of the sampling scheme,

334 was calculated as $-\hat{b}_{F} /\left(1-\bar{F}_{(1)}\right)$; where $\hat{b}_{F}$ is the slope of the linear regression of $\bar{F}_{(d)}$ 335 on the natural logarithm of the geographic distance, and $\bar{F}_{(1)}$ is the mean $F_{i j}$ over the 336 first distance class. In this formula, the first distance class is supposed to contain all 337 (nearest) neighbour pairs. Since $98 \%$ of neighbour pairs of trees were in the $0-20 \mathrm{~m}$ 338 distance class, the distance limits were set to 20, 30, 40, 50, 100, 200, 300, 400, 500, 339 and $1000 \mathrm{~m}$.

340 To assess the potential impact of clonal growth form on SGS, a preliminary 341 analysis was performed at the tree level, in which all ramets within a MLL were 342 assigned the same genotype; a second analysis was then performed at the MLL level. In 343 the first analysis, the significance of $\bar{F}_{(d)}$ and $\hat{b}_{F}$ were assessed by 10000-permutation 344 tests based on the geographic locations of trees. In the second analysis, a 10000345 resampling approach was used, in which one ramet was randomly selected from each 346 MLL at each resampling step (Alberto et al. 2005). This yielded a 95\% confidence 347 interval for $\bar{F}_{(d)}$ for each distance class. The significance of $\hat{b}_{F}$ was assessed as above. 348

349 Results 
351 Clonality

352

353 The genotypic resolution followed an asymptotic trend (Fig. 2), where the gain from

354 using additional markers increased sharply between one and four loci and appeared to

355 stabilize at very low values when there were more than six loci (i.e., less than 5\% 356 additional MLGs identified per additional locus).

357 Among the 413 trees, we were able to genotype 379 fully at the 11 SSR loci and 358 these clustered into 222 MLGs. All ramets within a MLG were associated with a $p_{\text {sex }}$ 359 value below $10^{-7}$. The 34 remaining trees had one (22), two (8), three (3) or four (1) 360 loci missing. By sequentially removing the missing loci before re-analysing the data, it 361 was possible to assign 22 of these trees to previously identified MLGs $\left(p_{\text {sex }}<10^{-5}\right)$. By sequentially removing the mismatched loci for MLGs differing at only one locus, these MLGs could be clustered into 37 MLLs $\left(p_{\text {sex }}<10^{-5}\right)$. A total of 194 distinct MLLs were

364 therefore identified, of which $79 \mathrm{MLL}_{\geq 2}$. The resulting genotypic richness $(R)$ was

365 0.47. Sex data were consistent with this grouping since all ramets within a MLL were of 366 the same gender.

367 MLL size $\left(N_{R}\right)$ ranged from one to 18 ramets, but $95 \%$ of MLLs contained 368 fewer than five ramets (Fig. 3). The logarithm of the cumulative distribution of ramets 369 among MLLs was significantly linearly related to the logarithm of $N_{R}$ (Fig. 3), thus 370 supporting the Pareto distribution hypothesis. The associated patchiness exponent 371 estimate was $\beta=1.07$.

372 Clonality appeared to be evenly distributed through the study site since 373 differential plotting of individuals belonging to unreplicated genotypes, to small MLLs 
and to large MLLs did not reveal any structured geographical pattern (Fig. 4). MLL geographic size, as measured by the maximum distance between two ramets $\left(d_{\max }\right)$, ranged from 0.9 to $30.3 \mathrm{~m}$. The intra-MLL average distance between nearest neighbours

$377\left(\bar{d}_{n e i g h b}\right)$ ranged from 0.9 to $18.6 \mathrm{~m}$. A significant linear relationship was found between $N_{R}$ and $d_{\max }$ (Fig. 5). Although resulting in a non significant linear correlation

379 coefficient, a triangular relationship was found between $N_{R}$ and $\bar{d}_{\text {neighb }}$ : MLLs with few

380 ramets were associated with a large range of $\bar{d}_{n e i g h b}$ values while low $\bar{d}_{\text {neighb }}$ values

$381(\leq 5 \mathrm{~m})$ were consistently found in MLLs containing six or more ramets (Fig. 5). A 382 similar relationship was found between $N_{R}$ and mean or individual tree girth (singlestemmed individuals only): high ramet numbers were associated with low girths while MLL sizes ranging from one to five were associated with a large range of girth values (Fig. 6).

The estimated aggregation index $\left(A_{c}\right)$ was $0.62 \quad(P<0.001)$, indicating significant spatial clustering of clonal ramets compared to the whole population. The mean clonal dominance index $\left(\bar{D}_{c}\right)$ was 0.99 , indicating that the spatial range of a MLL was almost exclusively occupied by ramets belonging to that MLL. This parameter differed from 1 in only two $\mathrm{MLL}_{\geq 3}\left(D_{c}=0.67\right.$ and 0.71$)$.

392 Introgression from the Lombardy poplar

394 Of the thirteen Lombardy poplars sampled, eleven were similar to the San Giorgio 395 reference genotype at all studied loci. Although belonging to the main group of eleven 396 trees forming a row on a campsite nearby, the two others differed from the San Giorgio 397 genotype at one and two loci, respectively. These differences always corresponded to 
398 one-repeat-unit changes and were restricted to one allele per differing locus. Genotyping 399 newly collected leaves led to the same results, suggesting somatic mutations had 400 occurred before planting.

401 Five $\mathrm{MLL}_{=1}$ (two males and three females, girth $=41,159,164,189$, and $208 \mathrm{~cm}$ ) were 402 identified as possible $F_{1}$ hybrids of the San Giorgio genotype. Some alleles from this 403 genotype were found at very low frequencies in the MLLs (e.g., $f=0.008$ at locus 404 PMGC2852), thus resulting in low probabilities of false paternity assignment $405\left(7.7 \times 10^{-5} \leq P_{\text {non-excl. }} \leq 2.7 \times 10^{-3}\right)$. None of the identified introgressed hybrids 406 exhibited the typical columnar shape of the Lombardy poplar. Core-analysis of three of 407 them revealed ages of $12.5,53$, and 45.5 years (girth $=41,159$, and $208 \mathrm{~cm}$, 408 respectively). All five individuals were removed from subsequent analyses. No potential $409 \mathrm{~F}_{1}$ progeny from any of the two identified somaclonal mutants of San Giorgio was 410 found.

412 Genetic diversity

414 The sex-ratio was $1: 0.92$ on an individual tree basis, which was not significantly 415 different from a $1: 1$ ratio (Table 1). As no significant difference was found between 416 males and females for both the number of $\mathrm{MLL}_{\geq 2}$ (40 and 39, respectively) and the 417 mean number of ramets per $\mathrm{MLL}_{\geq 2}$ (i.e., $N_{R}=4.1$ and 3.4, respectively, $P=0.50$ ), the 418 sex-ratio was also balanced at the MLL level (Table 1).

419 The level of polymorphism was highly variable among the 11 studied loci, 420 ranging from four (PMGC333) to 22 alleles (PMGC667). High rates of rare alleles led 421 to a two-fold difference between mean observed and effective allele numbers, $\bar{A}$ and 
$422 \bar{A}_{e}$ (Table 2). Compared to the nine other loci, PMGC433 and PMGC2838 combined

423 low polymorphism, high rates of rare alleles, and (possibly as a consequence) lower

424 observed and expected heterozygosities, $H_{o}$ and $H_{e}$. Mean $\bar{H}_{o}$ and $\bar{H}_{e}$ values were

425 very close, leading to a non-significant overall $F_{\text {is }}$ (Table 2). Two loci (PMGC2852 and

426 PMGC333) exhibited significant heterozygote excess and three (PMGC667,

427 PMGC2838 and WPMS05) significant deficit (Table 2).

428

429 Spatial genetic structure

430

431

At the tree level, the regression of $F_{i j}$ over the natural logarithm of the geographic distance produced a significantly negative regression slope $\left(\hat{b}_{F}=-0.0263\right.$, $P<0.001$ ), indicating higher genetic similarity among trees that were closer together. A significant positive mean kinship coefficient was found in the first distance class only $\left(d_{1}=0-20 \mathrm{~m}, \quad \bar{F}_{(1)}=0.1870 ;\right.$ Fig. 7$)$. At the MLL level, the kinship-distance

436 regression slope was much shallower, but still significant $\left(\hat{b}_{F}=-0.0045, P=0.001\right.$;

437 Fig. 7). The $S p$ statistic was seven-fold smaller at the MLL level than at the tree level, 438 decreasing from 0.0324 to 0.0046 , while $\bar{F}_{(1)}$ decreased to 0.0230 .

440 Discussion

SSRs have proved efficient in poplars for fingerprinting and for detecting 443 introgression from different species (Fossati et al. 2003; Liesebach et al. 2010; 444 Smulders et al. 2008a). Despite the fact that it belongs to the P. nigra species, the 
445 Lombardy poplar (i.e., the San Giorgio reference genotype) carried some alleles that 446 were comparatively rare in the studied P. nigra population. This allowed us to consider $4472.6 \%$ of MLLs being probable $\mathrm{F}_{1}$ hybrids of this cultivar with low probabilities of false 448 paternity assignment. Of course, these probabilities are based on the hypothesis that the 449 allelic frequencies observed within the studied population are representative of the 450 population's parental gene pool. However, poplar seeds are dispersed by water over 451 long distances, and Lombardy poplars are very frequent in rural and urban landscapes of 452 the Loire Valley. It is thus expected that introgression events, if any, would most 453 probably originate from crosses upstream of the study site. This idea is supported by age 454 inconsistencies between the studied Lombardy poplar trees and most of the probable 455 introgressed $F_{1}$ individuals, and also by the fact that the two Lombardy poplar 456 somaclonal mutants found at close vicinity of the study site were not found to be 457 potential parents of any studied tree. When trying to identify introgression events from 458 the Lombardy poplar in natural P. nigra stands, Imbert and Lefèvre (2003) also reported 459 rare alleles at one SSR locus but only mentioned a rough estimate of a few percent 460 introgressed genotypes. Other studies have reported introgression levels between $0 \%$ 461 (Tabbener and Cottrell 2003), and 1.6\% (Vanden Broeck et al. 2004). Both these studies 462 concluded that there was a negligible threat to local black poplar populations because of 463 the early flowering of the Lombardy poplar, and a consequent lack of synchronism with 464 P. nigra females of northern origin. We do not share this optimistic point of view for 465 two main reasons, namely (i) an underestimation of introgression rates due to the fact 466 that advanced-generation intraspecific hybrids cannot be detected with high levels of 467 confidence and (ii) weak support for the asynchronism hypothesis in a species with a 468 wide distribution area, especially in the context of a changing climate. Moreover, the 
469 five probable identified introgressed individuals were not recognizable based on their

470 phenotype with respect to branching. We thus suspect that genotyping existing ex-situ

471 collections of $P$. nigra to check for possible introgression from Italica would produce

472 surprising results.

473 In previous studies, SSR analysis of commercial cultivars from different taxa

474 (Fossati et al. 2003; Liesebach et al. 2010) and natural P. nigra stands (Barsoum et al.

475 2004; Pospiskova and Bartakova 2004; Pospiskova and Salkova 2006; Rathmacher et

476 al. 2010; Smulders et al. 2008b) allowed detection of replicated genotypes. When

477 considering the evolution of marginal gain in terms of additional differentiated MLGs

478 per additional locus, the 11 SSRs used in the present study allowed a genotypic

479 resolution close to optimum. Indeed, although "clonality is merely a genotype resolution

480 phenomenon dependent upon the resolution power of molecular markers culminating

481 with direct sequencing of DNA' (Lushai and Loxdale 2002), increasing the number of

482 markers not only allows the detection of rare somatic mutation events but also increases

483 the chance of scoring errors occurring. Somatic mutations are expected to occur at

484 significant rates for SSRs, for which high mutation rates ranging from $10^{-7}$ to $10^{-3}$ per 485 locus per generation have been reported in eukaryotes (Buschiazzo and Gemmell 2006).

486 As an illustration, two somatic mutants were identified among the thirteen Lombardy 487 poplars analysed here. However, using the standardized procedure proposed by Arnaud488 Haond et al. (2007), MLGs differing at only one locus were grouped into MLLs despite 489 their somatic-mutant vs. scoring-error status. Reviewing the data, it appears that there 490 are only four circumstances out of 45 for which a mutational event corresponding to the 491 Stepwise Mutation Model could be hypothesized (i.e., both MLGs heterozygous with a 492 one-repeat allelic difference). Somatic mutations may be useful tools, acting as a 
493 molecular clock in many clonal cells or organisms including poplars (Ally et al. 2008;

494 Mock et al. 2008). Nevertheless, there are many pitfalls in their analysis including (i) a

495 lack of knowledge about mutation rates during mitosis, (ii) a complex heterogeneity of

496 mutational events at allele, locus, individual and/or taxon levels, and, again, (iii) the

497 difficulty in distinguishing between true somatic mutations and scoring errors (Heinze

498 and Fussi 2008).

499 The population studied exhibited substantial asexual recruitment. If one ramet

500 per MLL represented a potential founder, then $53 \%$ of the population originated from

501 vegetative propagation. The genotypic richness $(R=0.47)$ was intermediate within the

502 range of values found in other P. nigra studies (or computed from them when not

503 originally expressed as $G-1 / N-1$ ). Considering clumped trees to be clonal ramets, as

504 suggested by Barsoum et al. (2004), would lead to even lower genotypic richness

505 values. $R$ values across all studied European $P$. nigra stands found in the literature

506 appear to follow a distribution skewed towards higher values, with fifteen values out of

507 nineteen falling between 0.8 and 1 and only three occurrences below 0.2 (Arens et al.

508 1998; Barsoum et al. 2004; Legionnet 1997; Pospiskova and Bartakova 2004;

509 Pospiskova and Salkova 2006; Rathmacher et al. 2010; Smulders et al. 2008b). Very

510 low values of 0.01 and 0.04 have also been reported in mature stands in Great Britain

511 (Smulders et al. 2008b) and in the Netherlands (Arens et al. 1998), respectively,

512 although both sampling schemes were designed to avoid collecting clonal individuals.

513 In contrast, despite a nearest neighbour sampling strategy, Barsoum et al. (2004) found

514 high $R$ values (>0.8) in three age cohorts, with a significantly higher number of clonal

515 ramets in the 'middle-aged' stands (8 years old) than in both the 'young' (5.6 years old)

516 and 'old' (17.6 years old) stands. Sampling in this previous study covered islands and 
517 gravel bars, each of them having certainly been more favourable (spatially and 518 temporally) for seedling recruitment and also less affected by anthropogenic disturbance

519 than our study site. Tree densities were consistently higher on the islands and gravel 520 bars than those recorded in Saint-Ay $\left(0.2\right.$ trees. $\mathrm{m}^{-2}$ in 'old' stands vs. 0.006 trees. $\mathrm{m}^{-2}$ in 521 the current study), and the existence of more dynamic sites certainly explained why the 522 'old' cohorts encountered by Barsoum et al. (2004) were much younger than most 523 individuals examined by us. Vegetative propagation in Saint-Ay certainly benefited 524 from the availability of open space, although the sites available for colonization were generally unfavourable (spatially and temporally) for seedling recruitment.

The MLL size $\left(N_{R}\right)$ distribution was skewed towards smaller values, ranging

527 from one to 18 ramets and exhibiting exponential decay. In previous studies, only small 528 clones of two to four ramets have been observed (Barsoum et al. 2004; Legionnet 1997; 529 Rathmacher et al. 2010) while Arens et al. (1998) and Smulders et al. (2008b) found 530 larger clones of up to 22 and 32 ramets, respectively. A clone size of 70 ramets was 531 recently reported in a British population, but this was probably planted (Smulders et al. 532 2008b). The $\beta$ Pareto index associated with the partitioning of ramets among MLL size 533 classes should allow reliable comparisons between studies. The present study provides a 534 first estimate of $\beta$ in $P$. nigra. The calculated value (1.07) was moderate in comparison 535 with those presented in a literature review pertaining to several clonal species (Arnaud536 Haond et al. 2007). These authors reported extreme values of 0.06 (Posidonia oceanica) 537 and 2.96 (Sinularia flexibilis), indicating dominance of some large clonal patches and 538 high evenness, respectively. They also provided the only reference available for a tree 539 species, namely Prunus ssiori $(\beta=0.88)$. 
540 Considering within-clone, between-clone, and between-species contacts, Lovett

541 Doust (1981) recognized a spectrum of growth forms in clonal plants, with the two 542 extremes referred to as 'phalanx' and 'guerrilla' forms. The high aggregation $543\left(A_{c}=0.62\right)$ and clonal dominance $\left(D_{c}=0.99\right)$ indexes computed in the present study 544 allow us to conclude that $P$. nigra exhibits a typical 'phalanx' growth form, where 545 ramets of the same MLL are aggregated and do not share their space with ramets of any 546 other MLL. Despite being less explicit, all published data on P. nigra clonal growth are 547 also indicative of a 'phalanx' growth form with zero or near-zero intermingling of 548 clones (Barsoum et al. 2004; Legionnet 1997). Although only possible with non549 exhaustive sampling strategies, larger study areas have allowed the identification of 550 long distance dispersal events up to $19 \mathrm{~km}$ (Barsoum et al. 2004), while the maximum 551 distance found in the current study was $d_{\max }=30.3 \mathrm{~m}$. The significant positive 552 correlation between $N_{R}$ and $d_{\max }$ and the absence of a significant correlation between $N_{R}$

553 and $\bar{d}_{n e i g h b .}$ may indicate that clonal growth in this open habitat is an expansion process 554 rather than one that leads to a densification of clonal patches. The triangular 555 relationships found between $N_{R}$ and both $\bar{d}_{\text {neighb }}$. and girth need further examination, 556 however. The fact that the MLLs with high ramet numbers comprised small trees 557 growing close together could be the result of either poor-quality, stressful, micro-habitat 558 conditions promoting vegetative propagation, or a possible genotypic trade-off between 559 the number and size of ramets, as found in other clonal species (Stuefer et al. 2002), 560 Although the whole study site appeared to be favourable for clonal propagation, and 561 although a significant correlation was found between girth and age, the first hypothesis 562 cannot be rejected. More precise tree ages and thus, more detail pertaining to intra-MLL 563 age structure, would facilitate investigations and interpretations. Core analysis is, 
564 however, very difficult in P. nigra wood, as experienced here, and root age would 565 certainly be more informative than stem age when studying clonal growth. It has been 566 hypothesized that flood training is a key mechanism of asexual regeneration in $P$. nigra

567 (Barsoum et al. 2004), but we did not observe the linear ramet distributions associated 568 with this type of sprouting frequently at the study site. Although no excavation was

569 conducted, root suckering seems the most probable type of vegetative spread on this 570 site. The aggregated pattern could thus result from the emergence of new shoots from 571 the parental root system and be maintained by the selective advantage of permanent or 572 at least transient physiological integration (i.e., physical links between ramets) over 573 fragmentation, as expected in habitats with restricted favourable patches compared to 574 unfavourable ones (Oborny and Kun 2002). However, inferring the temporal dynamics 575 of clonal growth from spatial structure at a single time point can be problematic for 576 three reasons: (i) the difficulty of disentangling the timing of the colonization process 577 from density-dependent events (e.g., both recent colonization in an empty space and 578 competitive exclusion can result in a segregated distribution); (ii) there are possible 579 trade-offs between clonal growth forms of a given species under different 580 environmental conditions (Ye et al. 2006); and (iii) community-level analysis, including 581 among-species interactions, is required (Gough et al. 2002).

582 SSR-based observed and expected heterozygosities found in the literature for 583 P. nigra vary within the ranges $0.67-0.93$ and $0.65-0.90$, respectively (Fossati et al. 584 2003; Imbert and Lefèvre 2003; Pospiskova and Bartakova 2004; Pospiskova and 585 Salkova 2006; Rathmacher et al. 2010; Smulders et al. 2008b; Storme et al. 2004; Van 586 Dam and Bordacs 2002). The values reported here $\left(\bar{H}_{o}=0.68, \bar{H}_{e}=0.69\right)$ are very 587 close to the lower limits. Overall, the value of $F_{i s}(0.008$, n.s.) did not indicate any 
588 significant deviation from Hardy-Weinberg equilibrium. Since no significant difference

589 was found between male and female vegetative propagation potentials, the sex-ratios

590 were equally balanced at both the tree and MLL levels. We are not aware of any

591 previously published data on the relative vegetative propagation potential of the two

592 genders of P. nigra.

593 Clonality was the main driver of SGS in the studied population. In total, $90 \%$ of

594 the identified $M L L_{\geq 2}$ exhibited a $d_{\max }$ falling within the distance range of significant

595 kinship coefficients $\left(F_{i j}\right)$ found at the tree level $(0-20 \mathrm{~m})$. Both the slope $\left(\hat{b}_{F}\right)$ of the

596 linear regression of $F_{i j}$ over the natural logarithm of geographic distance and the

597 associated $S p$ statistic sharply decreased at the MLL level. The presence of significant

598 residual SGS at the MLL level is consistent with two recent reports relating to $P$. nigra

599 (Pospiskova and Salkova 2006; Rathmacher et al. 2010). Although both studies

600 excluded clonal ramets from the analysis, they reported higher values for both $S p$

601 (0.0166 and 0.0146 vs. 0.0046 in the present study) and $\hat{b}_{F}(-0.0158$ and $-0.0136 v s$. -

602 0.0045). The scale of these previous studies was, however, much larger $(5 \mathrm{~km}$ and

$6032.5 \mathrm{~km}$, respectively), possibly leading to a sub-structuring of populations as suggested

604 by significant positive overall $F_{i s}$ values (i.e., the Wahlund effect). When calculating $S p$

605 statistics for 47 plant species, Vekemans and Hardy (2004) found values ranging from

6060.0003 to 0.2632 . They pointed out that the breeding system, life form (i.e., herbaceous,

607 small trees or trees), and population density were statistically linked to patterns of SGS.

608 When considered in isolation, pollen and seed-dispersal modes were not found to be

609 good predictors. Epperson (2007) expected unbalanced seeds vs. pollen dispersal

610 patterns to generate SGS, but experimental and theoretical data do not fully support

611 such a general trend (Ng et al. 2006; Sagnard et al. 2010). Results found in the literature 
612 from paternity (pollen) and parent-pair (seeds) assignments in P. nigra are scarce and

613 highly variable. Pospiskova and Salkova (2006) reported maximum distances for pollen

614 and seed dispersal of 230 and 370 m, respectively. Rathmacher et al. (2010) found that

$61550 \%$ of the pollen and $30 \%$ of the seeds of the species travelled more than $500 \mathrm{~m}$.

616 In- and ex-situ conservation can both benefit from a better description of

617 clonality. Past samplings in natural P. nigra stands across Europe for ex-situ 618 conservation have yielded a gene bank collection with $26 \%$ duplicated accessions

619 (Storme et al. 2004). Although some of the populations studied were probably 620 composed of vegetative copies propagated by humans and distributed over large areas 621 through cuttings, inappropriate sampling schemes certainly also contributed to this 622 result. Most studies on black poplar, including this one, reported a 'phalanx' growth 623 form usually with small numbers of ramets per clone. Consequently, duplications could 624 be minimized by using an appropriate sampling mesh in combination with sex 625 determination whenever possible. However, the deployment of high-throughput 626 molecular techniques would allow efficient detection of clones at limited cost: as few as 627 six SSR markers proved sufficient to identify $95 \%$ of the MLGs in the present study. 628 With respect to in-situ conservation, clone size $\left(N_{R}\right)$ distribution may be a critical factor 629 to take into account since the larger the number of ramets, the longer the clone may 630 survive under a gap disturbance regime, as has been simulated for $P$. tremuloides 631 (Namroud et al. 2006). However, these simulations were not spatially explicit. At the 632 species - rather than genotype - level, clonal growth form has been shown to affect 633 competitiveness in a plant community, with ramet aggregation reducing the competitive 634 ability of a clonal species in an open environment (Lenssen et al. 2005). Clustering can 635 also affect mating patterns in dioecious species (Charpentier 2002). In addition, possible 
636 trade-offs between sexual and asexual fecundities may occur, as documented for other

637 species (Sun et al. 2001) with different implications at the tree, clone or population 638 levels.

639

640

\section{Acknowledgments}

641

642

The authors thank Catherine Pasquier from INRA Orléans, UR Science du Sol,

643 for crucial field and laboratory assistance with the geographic information systems;

644 Vanina Guérin and Véronique Jorge from INRA Orléans, UR AGPF, for their help and

645 advice on SSR genotyping; Patrick Poursat and the INRA Orléans Experimental Unit

646 for assistance with fieldwork, and special thanks to Frédéric Millier for the increment

647 core sample collection and preparation; Françoise Laurans and Alain Moreau from

648 INRA Orléans, UR AGPF, for their meticulous help with the core analysis; Jean Dufour

649 from INRA Orléans, UR AGPF, and Michel Chantereau, Administrator of the Saint-

650 Mesmin French Natural Reserve, for floristic inventories; and two anonymous

651 reviewers who made very useful comments about this work and the resulting paper.

652 Nicolas Chenault was supported by a $\mathrm{PhD}$ grant co-financed by INRA and Conseil

653 Régional de la Région Centre, France. This study was carried out with financial support

654 from INRA (programme ECOGER, projet INTERPOPGER). 
Bibliography

656

657

658

659

660

661

662

663

664

665

666

667

668

669

670

671

672

673

674

675

676

677

678

679

680

681

682

683

684

685

686

687

688

689

690

691

692

693

694

695

696

697

698

699

700

Alberto F, Gouveia L, Arnaud-Haond S, Perez-Llorens JL, Duarte CM, Serrao EA (2005) Within-population spatial genetic structure, neighbourhood size and clonal subrange in the seagrass Cymodocea nodosa. Mol Ecol 14 (9):2669-2681

Ally D, Ritland K, Otto SP (2008) Can clone size serve as a proxy for clone age? An exploration using microsatellite divergence in Populus tremuloides. Mol Ecol 17 (22):4897-4911

Arens P, Coops H, Jansen J, Vosman B (1998) Molecular genetic analysis of black poplar (Populus nigra L.) along Dutch rivers. Mol Ecol 7 (1):11-18

Arnaud-Haond S, Alberto F, Teixeira S, Procaccini G, Serrao EA, Duarte CM (2005) Assessing genetic diversity in clonal organisms: Low diversity or low resolution? Combining power and cost efficiency in selecting markers. J Hered 96 (4):434-440

Arnaud-Haond S, Belkhir K (2007) GENCLONE: A computer program to analyse genotypic data, test for clonality and describe spatial clonal organization. Mol Ecol Notes 7 (1):15-17

Arnaud-Haond S, Duarte CM, Alberto F, Serrao EA (2007) Standardizing methods to address clonality in population studies. Mol Ecol 16 (24):5115-5139

Balloux F, Lehmann L, De Meeus T (2003) The population genetics of clonal and partially clonal diploids. Genetics 164 (4):1635-1644

Barsoum N (2002) Relative contributions of sexual and asexual regeneration strategies in Populus nigra and Salix alba during the first years of establishment on a braided gravel bed river. Evol Ecol 15 (4-6):255-279

Barsoum N, Muller E, Skot L (2004) Variations in levels of clonality among Populus nigra L. stands of different ages. Evol Ecol 18 (5-6):601-624

Buschiazzo E, Gemmell NJ (2006) The rise, fall and renaissance of microsatellites in eukaryotic genomes. BioEssays 28 (10):1040-1050

Cagelli L, Lefèvre F (1995) The conservation of Populus nigra L. and gene flow with cultivated poplars in Europe. For Genet 2 (3):135-144

Charpentier A (2002) Consequences of clonal growth for plant mating. Evol Ecol 15 (46):521-530

Cooper FM (2006) The black poplar: History, ecology and conservation. Windgather Press, Macclesfield, England

Cottrell JE, Forrest GI, White IMS (1997) The use of RAPD analysis to study diversity in British black poplar (Populus nigra L. subsp. betulifolia (Pursh) W. Wettst. (Salicaceae)) in Great-Britain. Watsonia 21 (4):305-312

Dickmann DI, Kuzovkina J (2008) Poplars and willows of the world, with emphasis on silviculturally important species. International Poplar Commission Working Paper IPC/9-2. FAO, Rome, Italy

Dorken ME, Eckert CG (2001) Severely reduced sexual reproduction in northern populations of a clonal plant, Decodon verticillatus (Lythraceae). J Ecol 89 (3):339-350

Epperson BK (1990) Spatial autocorrelation of genotypes under directional selection. Genetics 124 (3):757-771

Epperson BK (2007) Plant dispersal, neighbourhood size and isolation by distance. Mol Ecol 16 (18):3854-3865 
701

702

703

704

705

706

707

708

709

710

711

712

713

714

715

716

717

718

719

720

721

722

723

724

725

726

727

728

729

730

731

732

733

734

735

736

737

738

739

740

741

742

743

744

745

746

747

Excoffier L, Laval G, Schneider S (2005) Arlequin (version 3.0): An integrated software package for population genetics data analysis. Evol Bioinforma Online $1: 47-50$

Fossati T, Grassi F, Sala F, Castiglione S (2003) Molecular analysis of natural populations of Populus nigra L. intermingled with cultivated hybrids. Mol Ecol 12 (8):2033-2043

Frison E, Lefèvre F, De Vries SMG, Turok J, compilers (1995) Populus nigra Network. Report of the first meeting, 3-5 October 1994, Izmit, Turkey. IPGRI, Rome, Italy

Gautier E, Grivel S (2006) Multi-scale analysis of island formation and development in the Middle Loire River - France. International Symposium on Sediment dynamics and the hydromorphology of fluvial systems, IAHS, Wallingford, UK:179-187

Gough L, Goldberg DE, Hershock C, Pauliukonis N, Petru M (2002) Investigating the community consequences of competition among clonal plants. Evol Ecol 15 (46):547-563

Guilloy-Froget H, Muller E, Barsoum N, Hughes FMR (2002) Dispersal, germination, and survival of Populus nigra L. (Salicaceae) in changing hydrologic conditions. Wetlands 22 (3):478-488

Hartl DL, Clark AG (1997) Principles of population genetics, 3rd edn. Sinauer Associates, Sunderland, USA

Heinze B, Fussi B (2008) Somatic mutations as a useful tool for studying clonal dynamics in trees. Mol Ecol 17 (22):4779-4781

Heuertz M, Vekemans X, Hausman JF, Palada M, Hardy OJ (2003) Estimating seed vs. pollen dispersal from spatial genetic structure in the common ash. Mol Ecol 12 (9):2483-2495

Imbert E, Lefèvre F (2003) Dispersal and gene flow of Populus nigra (Salicaceae) along a dynamic river system. J Ecol 91 (3):447-456

IUCN (2010) IUCN Red List of Threatened Species. Version 2010.2. http://www.iucnredlist.org. Downloaded on 29 June 2010.

Jamieson A, Taylor SCS (1997) Comparisons of three probability formulae for parentage exclusion. Anim Genet 28 (6):397-400

Jones AG, Ardren WR (2003) Methods of parentage analysis in natural populations. Mol Ecol 12 (10):2511-2523

Koskela J, De Vries SMG, Kajba D, Von Wuhlisch G (2004) Populus nigra network. Report of the seventh (25-27 October 2001, Osijek, Croatia) and eighth meetings (22-24 May 2003, Treppein, Germany) IPGRI, Rome, Italy

Lefèvre F, Barsoum N, Heinze B, Kajba D, Rotach P, De Vries SMG, Turok J (2001a) In situ conservation of Populus nigra. IPGRI, Rome, Italy

Lefèvre F, Kajba D, Heinze B, Rotach P, De Vries SMG, Turok J (2001b) Black poplar: A model for gene resource conservation in forest ecosystems. For Chron 77 (2):239-244

Lefèvre F, Legionnet A, De Vries SMG, Turok J (1998) Strategies for the conservation of a pioneer tree species, Populus nigra L., in Europe. Genet Sel Evol 30 (Suppl. 1):S181-S196

Legionnet A (1997) Sexual and asexual reproduction in natural stands of Populus nigra. Bot Acta 110 (3):257-263 
Lenssen JPM, Hershock, C, Speek, T, During, HJ, De Kroon H (2005) Experimental ramet aggregation in the clonal plant Agrostis stolonifera reduces its competitive ability. Ecology 86 (5):1358-1365

Liesebach H, Schneck V, Ewald E (2010) Clonal fingerprinting in the genus Populus L. by nuclear microsatellite loci regarding differences between sections, species and hybrids. Tree Genet Genomes 6 (2):259-269

Loiselle BA, Sork VL, Nason J, Graham C (1995) Spatial genetic structure of a tropical understory shrub, Psychotria officinalis (Rubiaceae). Am J Bot 82:1420-1425

Lovett Doust L (1981) Population-dynamics and local specialization in a clonal perennial (Ranunculus repens). 1. The dynamics of ramets in contrasting habitats. J Ecol 69 (3):743-755

Lushai G, Loxdale HD (2002) The biological improbability of a clone. Genet Res 79 (1):1-9

Marshall TC, Slate J, Kruuk LEB, Pemberton JM (1998) Statistical confidence for likelihood-based paternity inference in natural populations. Mol Ecol 7 (5):639655

Mock KE, Rowe CA, Hooten MB, De Woody J, Hipkins VD (2008) Clonal dynamics in western North American aspen (Populus tremuloides). Mol Ecol 17 (22):4827-4844

Namroud M-C, Leduc A, Tremblay F, Bergeron Y (2006) Simulations of clonal species genotypic diversity: Trembling aspen (Populus tremuloides) as a case study. Conserv Genet 7 (3):415-426

Nei M (1978) Estimation of average heterozygosity and genetic distance from a small number of individuals. Genetics 89:583-590

Ng KKS, Lee SL, Saw LG, Plotkin JB, Koh CL (2006) Spatial structure and genetic diversity of three tropical tree species with different habitat preferences within a natural forest Tree Genet Genomes 2 (3):121-131

Oborny B, Kun A (2002) Fragmentation of clones: How does it influence dispersal and competitive ability? Evol Ecol 15 (4-6):319-346

Ohsako T (2010) Clonal and spatial genetic structure within populations of a coastal plant, Carex kobomugi (Cyperaceae). Am J Bot 97 (3):458-470

Paillassa E (2010) Où trouver les cultivars de peuplier pour les plantations 2009-2010? For Entrep 190:48-51

Parks JC, Werth CR (1993) A study of spatial features of clones in a population of bracken fern, Pteridium aquilinum (Dennstaedtiaceae). Am J Bot 80 (5):537-544

Pelée de Saint-Maurice (1762). L'art de cultiver les peupliers d'Italie, Veuve d'Houry, Paris, France.

Pospiskova M, Bartakova I (2004) Genetic diversity of a black poplar population in the Morava river basin assessed by microsatellite analysis. For Genet 11 (3-4):257262

Pospiskova M, Salkova I (2006) Population structure and parentage analysis of black poplar along the Morava River. Can J For Res 36 (5):1067-1076

Rathmacher G, Niggemann M, Kohnen M, Ziegenhagen B, Bialozyt R (2010) Shortdistance gene flow in Populus nigra L. accounts for small-scale spatial genetic structures: Implications for in-situ conservation measures. Conserv Genet 11 (4):1327-1338 
801

802

803

804

805

806

807

808

809

810

811

812

813

814

815

816

817

818

819

820

821

822

823

824

825

826

827

828

829

830

831

832

833

834

835

836

837

838

839

840

841

842
Reusch TBH, Hukriede W, Stam WT, Olsen JL (1999) Differentiating between clonal growth and limited gene flow using spatial autocorrelation of microsatellites. Heredity 83 (2):120-126

Rotach P (2004) Poplars and biodiversity. In: Populus nigra network. Report of the seventh (25-27 October 2001, Osijek, Croatia) and eighth meetings (22-24 May 2003, Treppein, Germany) IPGRI, Rome, Italy, pp 79-100

Sagnard F, Oddou-Muratorio S, Pichot C, Vendramin GG, Fady B (2010) Effects of seed dispersal, adult tree and seedling density on the spatial genetic structure of regeneration at fine temporal and spatial scales Tree Genet Genomes Online First. Accessed 27 June 2010

Smulders M, Beringen R, Volosyanchuk R, Vanden Broeck A, Van der Schoot J, Arens P, Vosman B (2008a) Natural hybridisation between Populus nigra L. and P. x canadensis Moench. Hybrid offspring competes for niches along the Rhine river in the Netherlands. Tree Genet Genomes 4 (4):663-675

Smulders MJM, Cottrell JE, Lefèvre F, Van der Schoot J, Arens P, Vosman B, Tabbener HE, Grassi F, Fossati T, Castiglione S, Krystufek V, Fluch S, Burg K, Vornam B, Pohl A, Gebhardt K, Alba N, Agundez D, Maestro C, Notivol E, Volosyanchuk R, Pospiskova M, Bordacs S, Bovenschen J, Van Dam BC, Koelewijn HP, Halfmaerten D, Ivens B, Van Slycken J, Vanden Broeck A, Storme V, Boerjan W (2008b) Structure of the genetic diversity in black poplar (Populus nigra L.) populations across European river systems: Consequences for conservation and restoration. For Ecol Manag 255 (5-6):1388-1399

Smulders MJM, Van der Schoot J, Arens P, Vosman B (2001) Trinucleotide repeat microsatellite markers for black poplar (Populus nigra L.). Mol Ecol Notes 1 (3): $188-190$

Stettler, R.F. (2009). Cottonwood and the River of Time: On Trees, Evolution, and Society, University of Washington Press, Seattle, USA.

Storme V, Vanden Broeck A, Ivens B, Halfmaerten D, Van Slycken J, Castiglione S, Grassi F, Fossati T, Cottrell JE, Tabbener HE, Lefèvre F, Saintagne C, Fluch S, Krystufek V, Burg K, Bordacs S, Borovics A, Gebhardt K, Vornam B, Pohl A, Alba N, Agundez D, Maestro C, Notivol E, Bovenschen J, Van Dam BC, Van der Schoot J, Vosman B, Boerjan W, Smulders MJM (2004) Ex-situ conservation of Black poplar in Europe: Genetic diversity in nine gene bank collections and their value for nature development. Theor Appl Genet 108 (6):969-981

Stuefer JF, Van Hulzen JB, During HJ (2002) A genotypic trade-off between the number and size of clonal offspring in the stoloniferous herb Potentilla reptans. J. Evol. Biol. 15:880-884.

Sun S, Gao X, Cai Y (2001) Variations in sexual and asexual reproduction of Scirpus mariqueter along an elevational gradient Ecol Res 16 (2):263-274

Tabbener HE, Cottrell JE (2003) The use of PCR based DNA markers to study the paternity of poplar seedlings. For Ecol Manag 179 (1-3):363-376

Van Dam BC, Bordacs S (2002) Genetic diversity in river populations of European black poplar. Proceedings of an International Symposium held in Szeksárd, Hungary from 16-25 May, 2001. Csiszár Nyomda, Budapest, Hungary

Van der Schoot J, Pospiskova M, Vosman B, Smulders MJM (2000) Development and characterization of microsatellite markers in black poplar (Populus nigra L.). Theor Appl Genet 101 (1-2):317-322 
Vanden Broeck A, Storme V, Cottrell JE, Boerjan W, Van Bockstaele E, Quataert P, Van Slycken J (2004) Gene flow between cultivated poplars and native black poplar (Populus nigra L.): A case study along the river Meuse on the DutchBelgian border. For Ecol Manag 197 (1-3):307-310

Vanden Broeck A, Villar M, Van Bockstaele E, Van Slycken J (2005) Natural hybridization between cultivated poplars and their wild relatives: Evidence and consequences for native poplar populations. Ann For Sci 62 (7):601-613

Vekemans X, Hardy OJ (2004) New insights from fine-scale spatial genetic structure analyses in plant populations. Mol Ecol 13 (4):921-935

Weir BS, Cockerham CC (1984) Estimating F-statistics for the analysis of population structure. Evolution 38 (6):1358-1370

Winfield MO, Arnold GM, Cooper F, Le Ray M, White J, Karp A, Edwards KJ (1998) A study of genetic diversity in Populus nigra subsp. betulifolia in the upper severn area of the UK using AFLP markers. Mol Ecol 7 (1):3-10

Wood C (1994) 'A most dangerous tree': The Lombardy poplar in landscape gardening. Arnoldia 54 (1):24-30

Ye XH, Yu FH, Dong M (2006) A trade-off between guerrilla and phalanx growth forms in Leymus secalinus under different nutrient supplies. Ann Bot 98 (1):187-191

Yonezawa K, Ishii T, Nagamine T (2004) The effective size of mixed sexually and asexually reproducing populations. Genetics 166 (3):1529-1539

Young AG, Hill JH, Murray BG, Peakall R (2002) Breeding system, genetic diversity and clonal structure in the sub-alpine forb Rutidosis leiolepis F. Muell. (Asteraceae). Biol Conserv 106 (1):71-78

868 


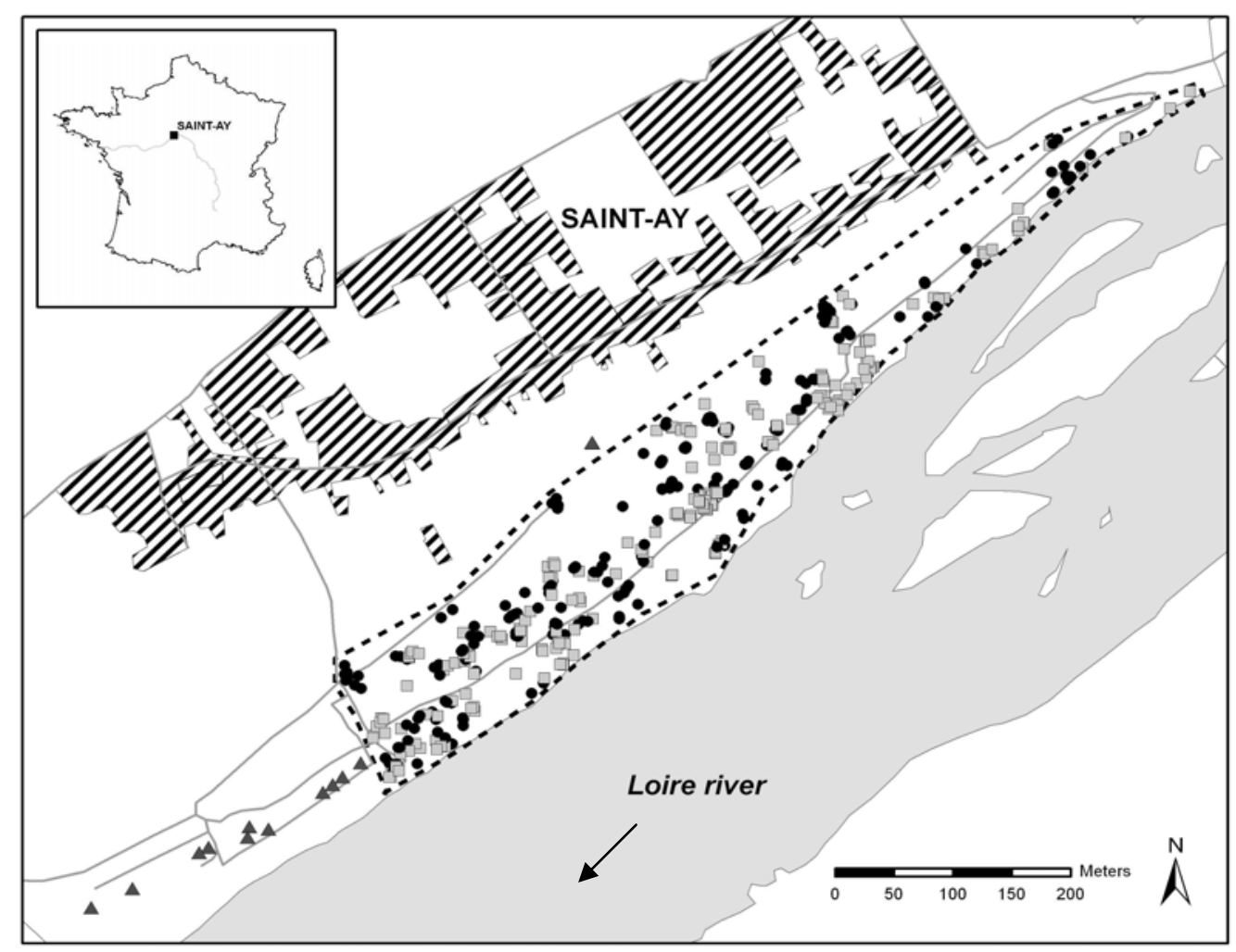

Fig. 1 - Study site (dotted line). Exhaustive inventory of adult trees within this 7 ha area revealed 199 female (black circles) and 214 male (grey squares) wild P. nigra trees. Triangles refer to the 13 sampled Lombardy poplars (non exhaustive inventory) used for genotyping and paternity analysis. 


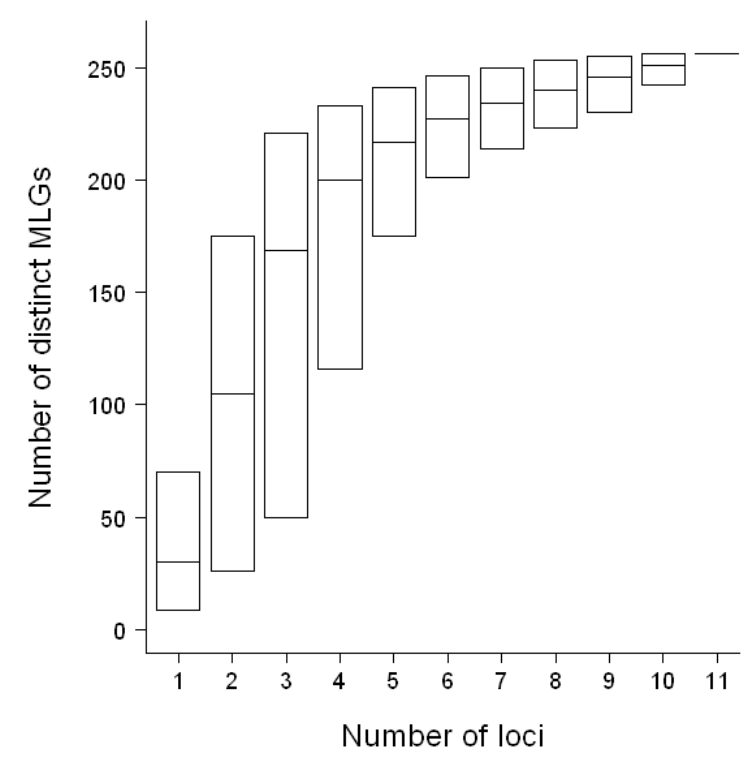

Fig. 2 - Genotypic resolution associated with each possible SSR combination. The boxes are bounded by the most and least informative combinations of loci. The inner line represents the mean value. 

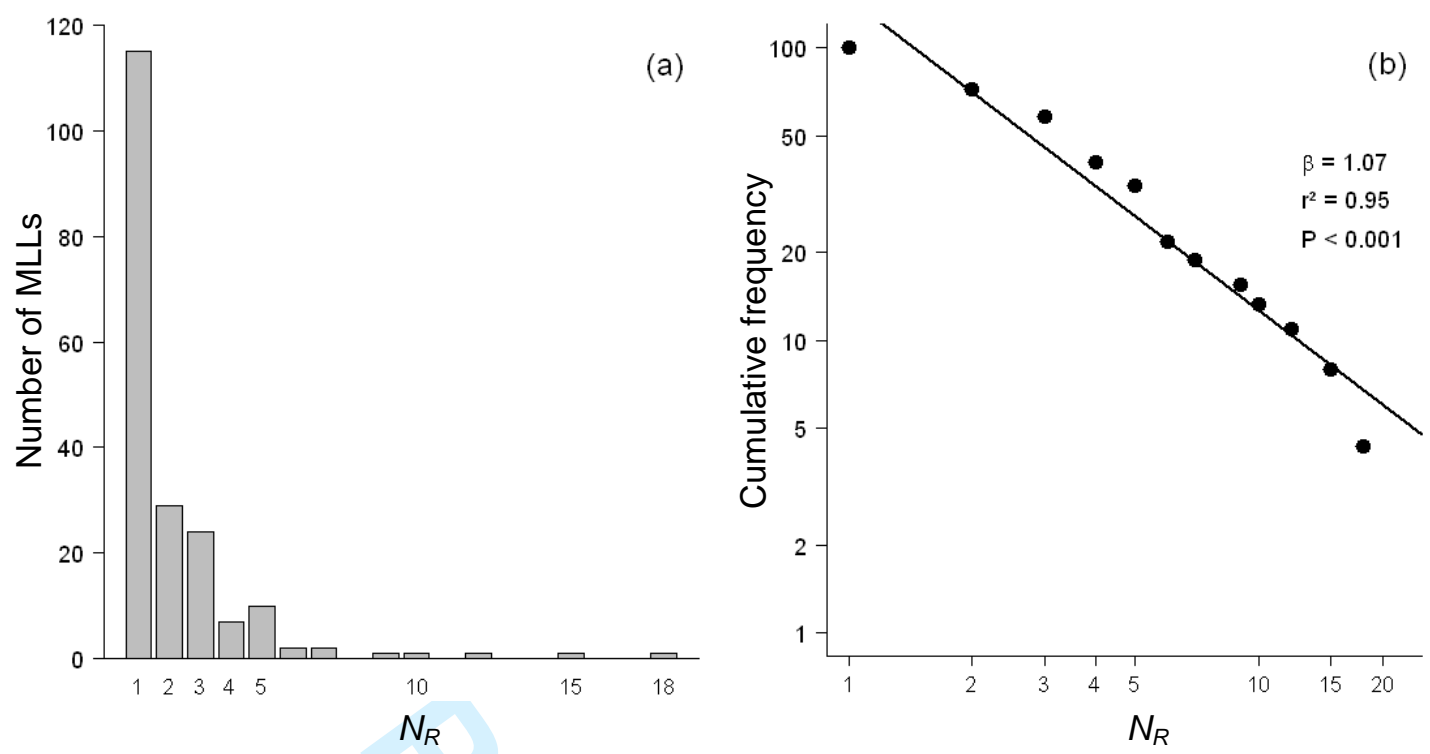

Fig. 3 - (a) Distribution of MLL size classes $\left(N_{R}\right.$, number of ramets) and (b) associated log$\log$ reverse cumulative frequency distribution. 


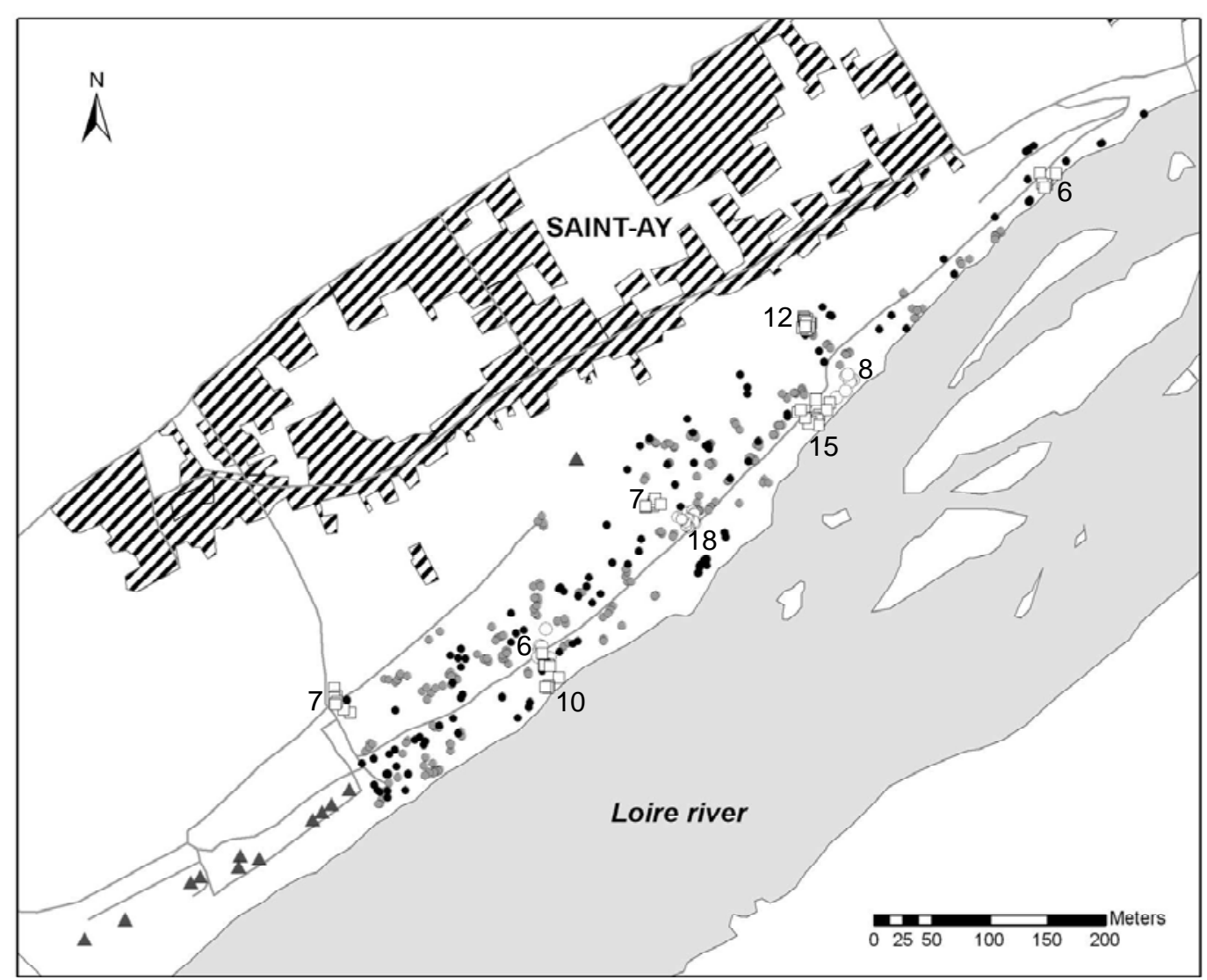

Fig. 4 - Differential plotting of studied individuals belonging to an $\mathrm{MLL}_{=1}$ (i.e., unreplicated individuals ; black dots), an $\operatorname{MLL}_{2 \leq N_{R} \leq 5}$ (grey dots), or an $\operatorname{MLL}_{\geq 6}$ (white dots and white squares with numbers indicating the corresponding ramet numbers). Triangles refer to the 13 sampled Lombardy poplars. 

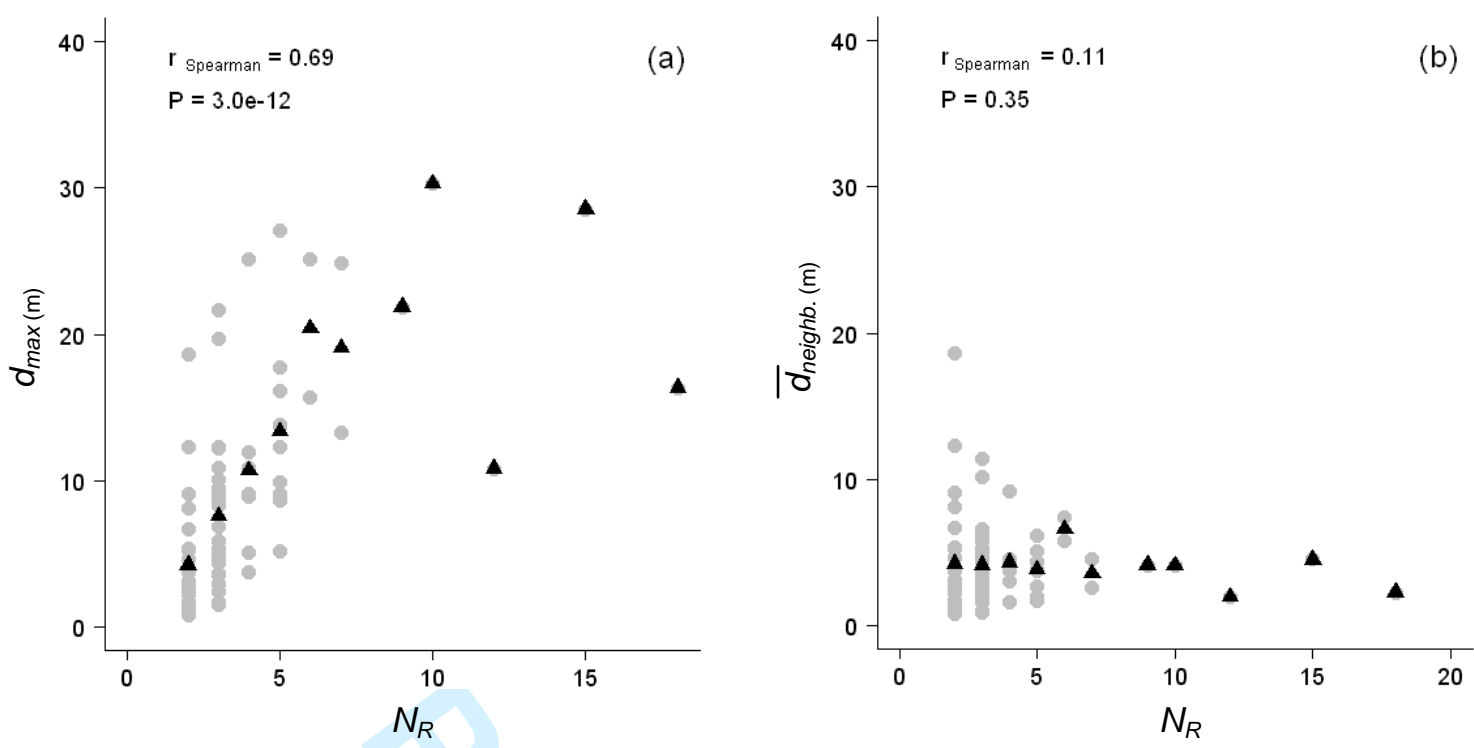

Fig. 5 - Relationships between MLL size $\left(N_{R}\right.$, number of ramets) and (a) the maximum distance between two ramets $\left(d_{\max }\right)$, (b) the mean distance between closest neighbours $\left(\bar{d}_{\text {neighb. }}\right)$. Mean values (black triangles) were computed for each $N_{R}$ class. Spearman's correlation coefficients were computed at the MLL level. 
1

2

3

4

5

6

7

8

9

10

11

12

13

14

15

16

17

18

19

20

21

22

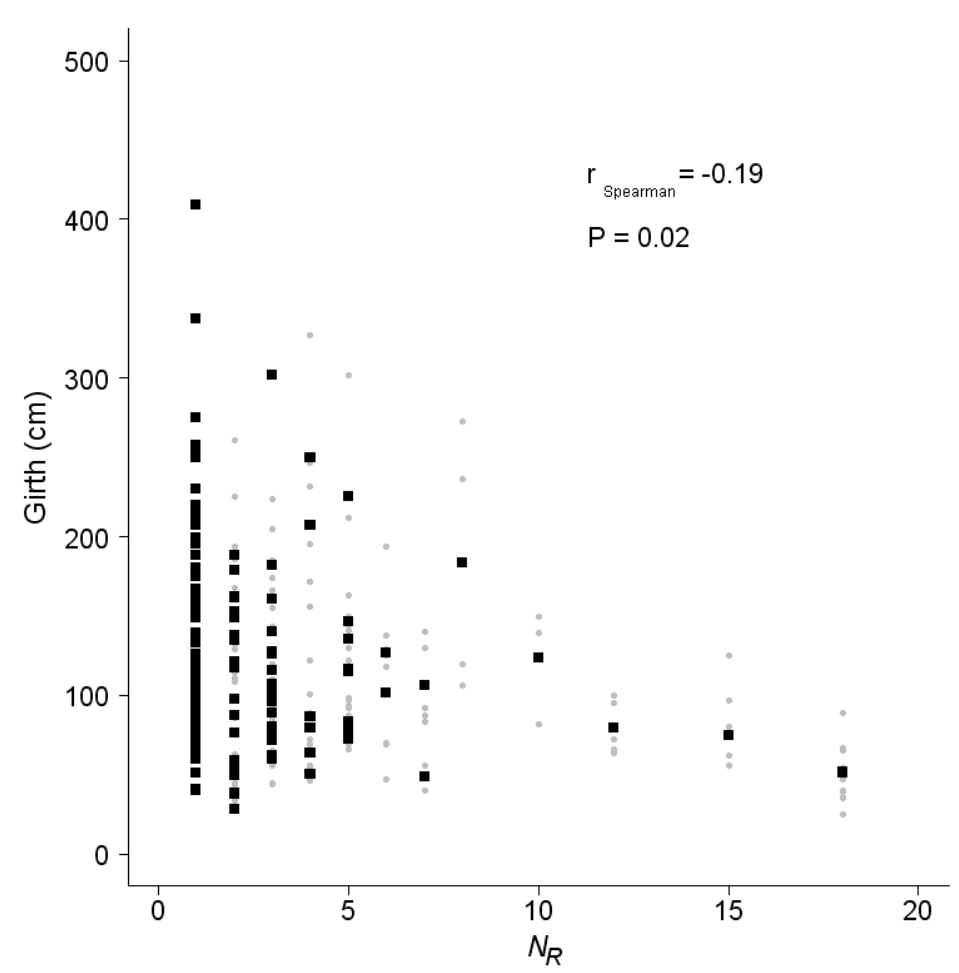

Fig. 6 - Relationships between MLL size ( $N_{R}$, number of ramets) and girth at breast height at the individual ramet level (grey dots) and at the MLL mean level (black squares). Analysis was restricted to single-stemmed individuals. Spearman's correlation coefficient was computed for the MLL mean level. 

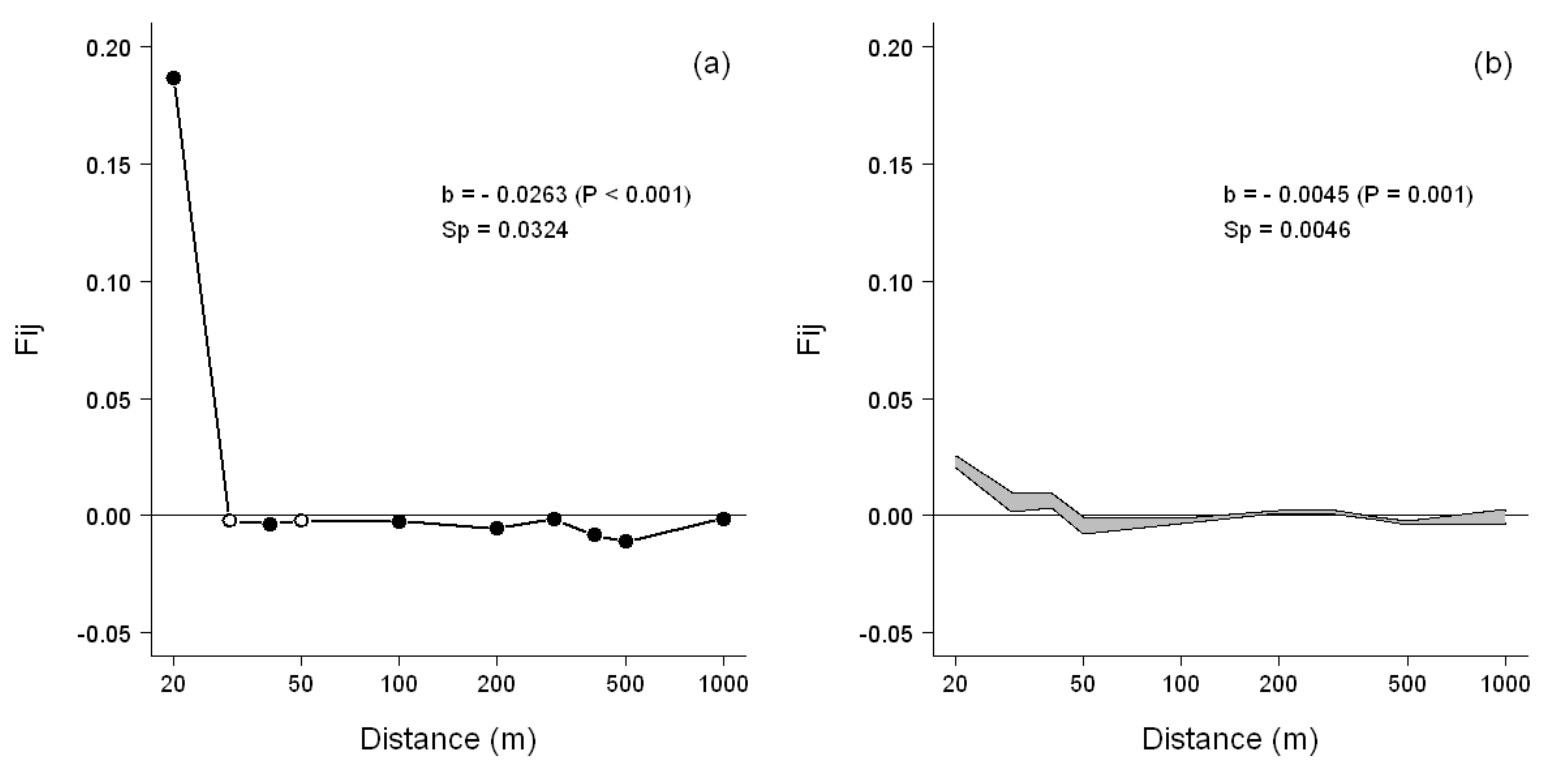

Fig. 7 - Spatial genetic structure analysis at (a) tree and (b) MLL levels. Both correlograms show the evolution of mean kinship coefficients $\left(F_{i j}\right)$ between pairs of sampling units over ten geographic distance classes. At the tree level, significant $(P<0.05)$ and non-significant mean $F_{i j}$ values are represented by black and white circles, respectively. At the MLL level, the envelope $(95 \% \mathrm{CI})$ is the result of a 10000-resampling procedure (a single ramet selected in each MLL at each resampling step). The five trees identified as probable $F_{1}$ siblings originating from the Lombardy poplar were removed from the analysis. 
Table 1 - Sex-ratio at tree and MLL levels with a distinction between mono-ramet $\left(\mathrm{MLL}_{=1}\right)$ and multi-ramet $\left(\mathrm{MLL}_{\geq 2}\right)$ MLLs. The five trees identified as probable $\mathrm{F}_{1}$ siblings originating from the Lombardy poplar were removed from the analysis.

\begin{tabular}{lllll}
\hline & Number of trees & \multicolumn{3}{c}{ Number of MLLs } \\
\cline { 3 - 5 } & & MLL $=1$ & MLL $_{\geq 2}$ & Total \\
\hline Males & 212 & 48 & 40 & 88 \\
Females & 196 & 62 & 39 & 101 \\
& & & & 189 \\
Total & 408 & 110 & & $1: 0.98$ \\
Sex-ratio & $1: 0.92$ & $1: 1.29$ & 0.91 & $1: 1.15$ \\
$P\left(>\chi_{1: 1}^{2}\right)$ & 0.43 & 0.18 & & 0.34 \\
\hline
\end{tabular}

Table 2 - Genetic diversity at the MLL level. The five trees identified as probable $\mathrm{F}_{1}$ siblings originating from the Lombardy poplar were removed from the analysis.

\begin{tabular}{|c|c|c|c|c|c|c|c|}
\hline Locus & LG & Motif & $\bar{A}$ & $\overline{A_{e}}$ & $\overline{H_{o}}$ & $\overline{H_{e}}$ & $F_{i s}{ }^{a}$ \\
\hline PMGC2852 & I & $(\mathrm{GA})_{\mathrm{n}}$ & 13 & 5.4 & 0.91 & 0.82 & $-0.12 * * *$ \\
\hline PMGC667 & II & $(\mathrm{GA})_{\mathrm{n}}$ & 22 & 9.1 & 0.73 & 0.89 & $0.19 * * *$ \\
\hline PMGC486 & III & $(\mathrm{GA})_{\mathrm{n}}$ & 10 & 5.3 & 0.85 & 0.81 & -0.05 \\
\hline PMGC2235 & IV & $(\mathrm{GA})_{\mathrm{n}}$ & 13 & 3.9 & 0.73 & 0.75 & 0.02 \\
\hline PMGC2838 & V & $(\mathrm{GA})_{\mathrm{n}}$ & 5 & 1.6 & 0.37 & 0.38 & $0.03 * *$ \\
\hline PMGC2578 & VI & $(\mathrm{GA})_{\mathrm{n}}$ & 15 & 4.3 & 0.74 & 0.77 & 0.04 \\
\hline PMGC61 & VIII & $(\mathrm{CTT})_{\mathrm{n}}$ & 7 & 4.3 & 0.74 & 0.77 & 0.04 \\
\hline PMGC333 & XI & $(\mathrm{CTT})_{\mathrm{n}}$ & 4 & 2.7 & 0.72 & 0.64 & $-0.14 * *$ \\
\hline WPMS05 & XII & $(\mathrm{GT})_{\mathrm{n}}$ & 14 & 6.8 & 0.83 & 0.86 & $0.03 *$ \\
\hline PMGC14 & XIII & $(\mathrm{GA})_{\mathrm{n}}$ & 7 & 3.9 & 0.76 & 0.75 & -0.01 \\
\hline PMGC433 & XVI & $(\mathrm{GA})_{\mathrm{n}}$ & 6 & 1.2 & 0.15 & 0.16 & 0.08 \\
\hline $\begin{array}{l}\text { Overall }{ }^{\mathrm{b}} \\
\pm \mathrm{SD}\end{array}$ & & & $\begin{array}{l}10.5 \\
\pm 5.4\end{array}$ & $\begin{array}{l}4.4 \\
\pm 2.3\end{array}$ & $\begin{array}{l}0.68 \\
\pm 0.23\end{array}$ & $\begin{array}{l}0.69 \\
\pm 0.22\end{array}$ & 0.008 \\
\hline
\end{tabular}

${ }^{a}$ Significant deviation from Hardy-Weinberg equilibrium : $* P<0.05 ; * * P<0.01 ; * * * P<0.001$

${ }^{\mathrm{b}}$ Mean value $\left(A, A_{e}, H_{o}\right.$, and $\left.H_{e}\right)$ or global sample estimate $\left(F_{i s}\right)$ 


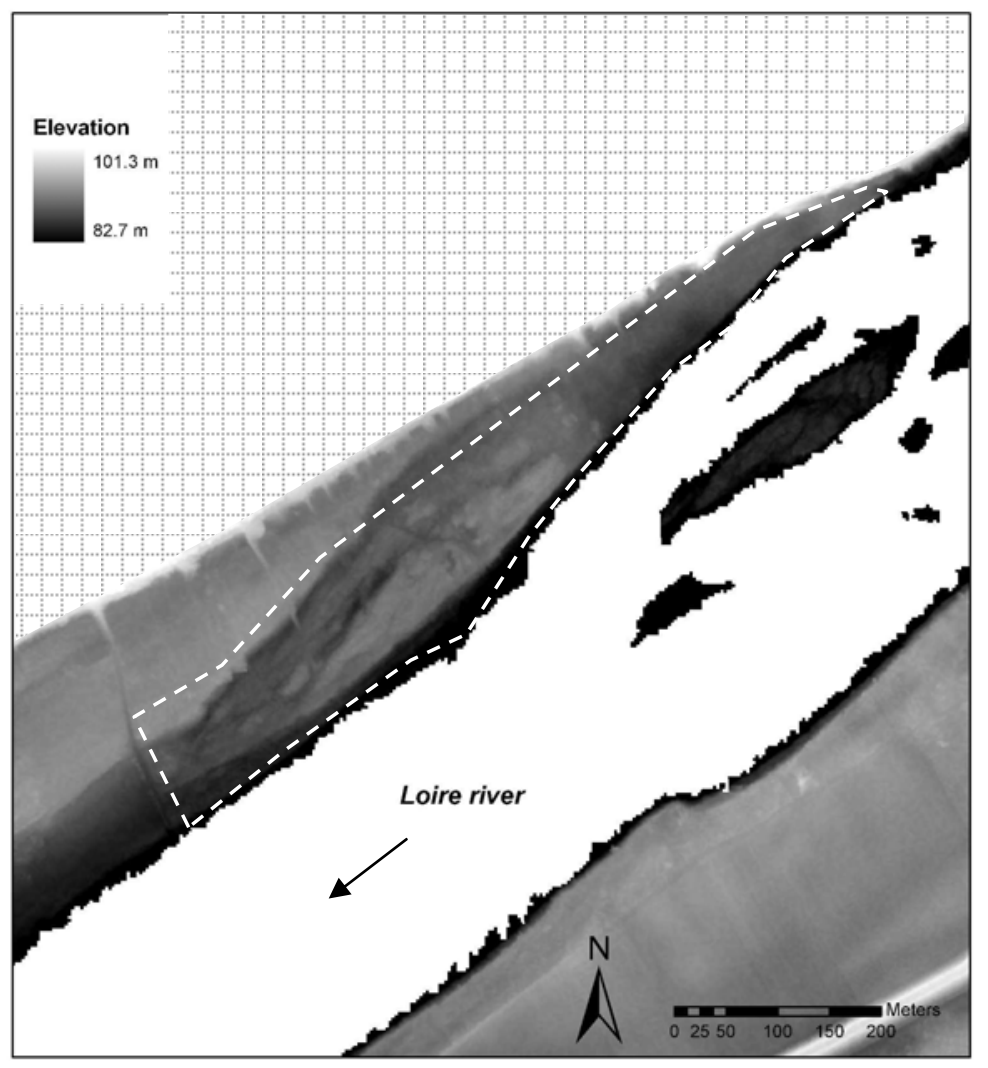

Supplementary Material 1 - Study site (dotted line) aircraft laser altimetry (data from Direction Régionale de l'Environnement de l'Aménagement et du Logement, Service Loire et Bassin Loire Bretagne, Orléans, France, 2002). 
Supplementary Material 2 - Relationship between tree height and girth at breast height and relative distributions of both traits within the studied wild $P$. nigra population (413 trees). The triangle refers to the mean point. In the case of clumped or forked trees, the girth of each stem was measured and the largest value was recorded. 


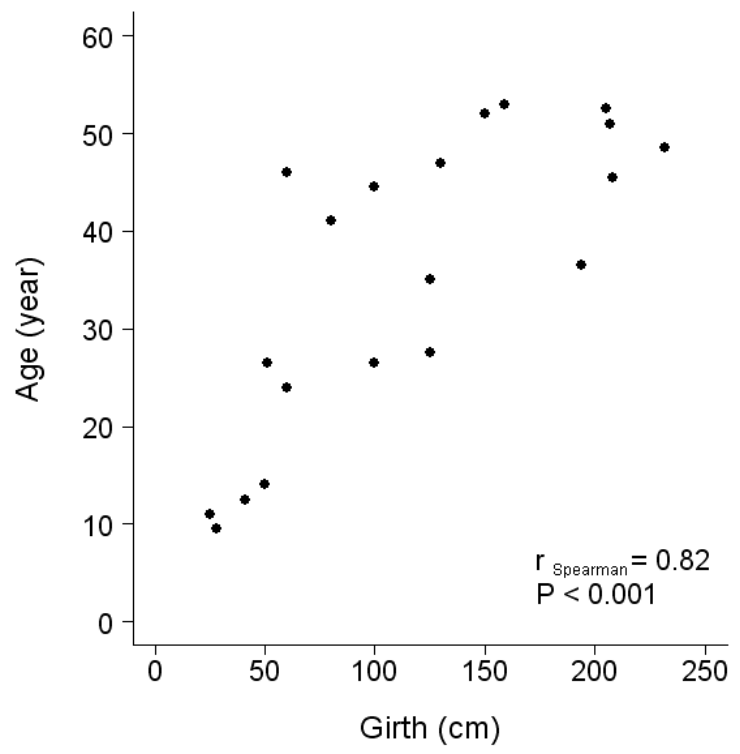

Supplementary Material 3 - Relationship between girth at breast height and tree age estimates (core analysis) on a subset (20 single-stemmed trees) of the studied P. nigra population. Increment core samples could not be collected from trees with a girth greater than $250 \mathrm{~cm}$. 